\title{
Role of Diffusion-Weighted Magnetic Resonance Imaging in Discrimination of Endometrial Carcinoma from Benign Diseases Affecting the Endometrium
}

\author{
NERMIN Y. SOLIMAN, M.D.*; MAHA M. ZAKI BILAL, M.D.*; \\ MOUSTAFA M. MOHAMED AL-KHIARY, M.D.**; EMAN M.H.M. ABO EL-ATA, M.D.* and \\ MARIAM Y.M. FARID, M.Sc.* \\ The Departments of Radiology* and Gynecology \& Obstetrics**, Faculty of Medicine, Mansoura University, Mansoura, Egypt
}

\begin{abstract}
Background: Evaluation of the role of diffusion-weighted imaging (DWI) in differentiation between endometrial carcinoma and benign diseases affecting the endometrium.

Aim of Study: To assess the efficacy and the diagnostic accuracy of DWI in discrimination of endometrial carcinoma from benign endometrial and subendometrial diseases with pathologic correlation.
\end{abstract}

Material and Methods: This study included 100 female patients with endometrial and subendometrial pathologies, their ages ranged from 20 to 85 years. Conventional T2weighted, pre- and post contrast T1-weighted and DW-MRI images with b values $0,500,1000 \mathrm{~s} / \mathrm{mm}^{2}$ were obtained. The mean ADC values of all lesions were recorded. Results were compared, correlated with final histopathological diagnosis reached by hysteroscopy, endometrial biopsy and surgical findings.

Results: Patients were divided according to the final histopathological diagnosis into two categories (category I: included 40 patients with endometrial carcinoma and category II: included 60 patients with benign endometrial and subendometrial diseases). In DWI qualitative analysis; all studied cases with endometrial carcinoma displayed high signal intensity, however; there was overlap in DWI SI as regard benign diseases. The mean ADC value of endometrial cancer was $0.73 \pm 0.10 \times 10^{-3} \mathrm{~mm}^{2} / \mathrm{s}$ which was significantly lower than that of benign diseases $1.36 \pm 0.32 \times 10^{-3} \mathrm{~mm}^{2} / \mathrm{s}(p<0.001)$ The cut off value for differentiation between endometrial cancer and benign diseases was $0.915 \times 10^{-3} \mathrm{~mm}^{2} / \mathrm{s}$ with sensitivity, specificity and accuracy of $97.5 \%, 88.3 \%$ and $92.0 \%$ respectively.

Conclusion: DWI combined with ADC measurement provides valuable information for evaluation of suspicious endometrial and subendometrial pathologies and is able to discriminate endometrial carcinoma from benign diseases affecting the endometrium with high diagnostic accuracy.

Key Words: Diffusion-weighted-MRI-DWI-ADC.

Correspondence to: Dr. Nermin Y. Soliman, The Department of Radiology, Faculty of Medicine, Mansoura University, Mansoura, Egypt

\section{Introduction}

ENDOMETRIAL carcinoma is one of the most widely recognized malignancies of the female genital tract, predominantly influencing postmenopausal women presented with abnormal vaginal bleeding, which is a non specific symptom since some benign pathologies affecting the endometrium may cause bleeding [1]

Radiologists considered endometrial pathologies to be a significant diagnostic challenge due to the potentially similar imaging features of benign and malignant endometrial lesions in morphological MRI [2,3] .

DWI is a recently widespread functional imaging method used to show tissue features dependent on the arbitrary dissemination movement of water particles, thereby giving a tissue contrast unique in relation to that appeared on conventional sequences [4]. DWI reflects alterations in proton mobility due to the changes of tissue cell density, cell membrane integrity and extracellular space tortuosity due to pathological conditions [5].

By performing DWI utilizing variable $b$-values, quantitative analysis, in particular, the estimation of apparent diffusion coefficient (ADC) values is available [5]. Several studies reported the value of estimating ADC in patients with endometrial carcinoma in distinction between normal and cancerous tissue and in discriminating benign from malignant uterine endometrial cavity pathologies [6] Areas characterized by hyperintense signal at DWI and low values of the ADC generally correspond with foci of high cellularity represents a malignant tissue [7]. 
So, the addition of DWI to conventional MRI can increase the specificity of lesion characterization [8], in order to obtain an accurate preoperative diagnosis and to avoid aggressive or unneeded surgical management [9].

\section{Patients and Methods}

This study included 100 female patients. Their ages ranged from 20 to 85 years old. It was conducted at the Diagnostic Radiology Department of Mansoura University Hospital over the period from July 2017 to July 2019.

Patients were referred from Obstetrics and Gynecology Department of Mansoura University Hospital \& Oncology Center, Mansoura University.

The study was approved by our institution's ethics committee, and all patients gave their informed consent before inclusion in the study.

\section{Inclusion criteria:}

- Patients with suspicious clinical findings as abnormal vaginal bleeding.

- Patients with suspicious sonographic findings as abnormal thickened endometrium not corresponding to patient age and menstrual status, and endometrial cavity mass.

\section{Exclusion criteria:}

- Patients with MRI incompatible devices.

- Claustrophobic patients.

- Patients with pathological results could not be obtained.

\section{All patients were subjected to the following:}

I- Full history taking with a special emphasis on: (Age, menstrual cycle, duration of menopause, history of replacement hormonal therapy, history of medical disease or anticoagulant therapy).

II- Clinical examination that was done by our colleagues in Obstetrics and Gynecology Department.

III- Routine laboratory investigation for all patients for example (complete blood picture, liver and kidney functions).

IV- Pelvic ultrasound examination.

V- MRI examination:

All MR examinations were performed using 1.5 MRI magnet (Philips-Enigma, the Netherlands) with a phased-array pelvic coil. Supine position was applied to all cases throughout the examination with head pointing towards the magnet (head first).
1- The conventional MRI sequences performed included non contrast T1-W sequence (TR 400600ms, TE $10-14 \mathrm{~ms}$ ) axial section, T2-WIs fast spin-echo (TR $3.000-6.000 \mathrm{~ms}$, TE 100-110ms) sagittal and oblique axial sections, Post contrast T1-WIs after fat suppression aquired in at least two planes after injection of Gadopentetate Dimeglumine (Magnevist) at a dose of $0.1 \mathrm{ml} / \mathrm{kg}$ body weight, the injection flow rate was $2 \mathrm{ml} / \mathrm{s}$, and the contrast injection was followed by a $20-\mathrm{ml}$ saline flush, Gadolinium-enhanced T1-WIs was performed after DWI utilizing the following parameters TR/TE $621 / 18 \mathrm{~ms}$, slice thickness $4-5 \mathrm{~mm}$; interslice gap 1-2mm; FOV $40 \times 28 \mathrm{~cm}$ and matrix was $256 \times 196$.

2- DWI MRI sequence was done before post contrast T1-WIs, by acquiring conventional T2WIs with addition of strong diffusion gradients using a single-shot echo-planar imaging sequence with the following parameters TR/TE $2640 / 80 \mathrm{~ms}$, slice thickness 5mm; interslice gap 1-2mm; FOV $40 \times 28 \mathrm{~cm}$ and matrix was 160 x 87 . Motionprobing gradient pulses are placed in the three orthogonal planes to generate isotropic DW images using a $b$ factor of 0,500 , and $1000 \mathrm{~s} / \mathrm{mm}^{2}$. Fat suppression was used for background using a selective partial inversion recovery (SPIR) or short $\mathrm{T} 1$ inversion recovery (STIR).

All images were transferred to a workstation (Advantage Windows version 4.2-07, GE Healthcare) and the DWI sequence was post processed with commercial software (FuncTool, GE Healthcare) to obtain apparent diffusion coefficient (ADC). At first, the conventional and post contrast MRI sequences were evaluated then we correlate them with DWI and ADC map.

\section{A- Qualitative analysis:}

Refers to visual assessment of the SI of the lesions. The lesions SI were classified to low, intermediate and high signals compared to that of the myometrium.

\section{B- Quantitative analysis:}

ADC map were automatically generated by the software on the basis of the images obtained. Mean ADC values (multiplied by $10^{-3} \mathrm{~mm}^{2} / \mathrm{s}$ ) were calculated by drawing elliptical regions of interest (ROI) in one representative region as large as possible, however; care was taken to exclude necrotic and cystic areas on the basis of findings on T2-WI. We also avoid the normal junctional zone of the uterus, hemorrhagic areas and the fibrous core of the polyps. 


\section{Histopathologic correlation:}

Radiological data of MRI were analyzed. MRI data were compared to histopathological data; 82 patients underwent surgery, 9 patients underwent exision of the lesion by hysteroscopy and 9 patients underwent biopsy after dilatation and curettage.

\section{Statistical analysis:}

Statistical analysis was performed using statistical package for the social science (SPSS) software package version 22.0. Monte Carlo test was used to compare SI of endometrial carcinoma and that of benign diseases affecting the endometrium on DWI. To compare the mean ADC values of benign endometrial and subendometrial diseases one way analysis of variance (ANOVA) test was used and Student $t$-test was used to compare the mean ADC of endometrial carcinoma and that of benign diseases. Probability $(p)$ values less than 0.05 were considered to be statistically significant. Receiver operating characteristic (ROC) analysis was used to evaluate the diagnostic capability of mean ADC values for differentiation between endometrial carcinoma and benign diseases. A value equal to the threshold or higher was considered to indicate a benign lesion, and a value below the threshold was considered to indicate a malignant lesion.

\section{Results}

This study included 100 female patients with endometrial and subendometrial pathologies, their ages ranged from 20 to 85 years old.

According to the final histopathological diagnosis, these patients were divided into two categories:

- Category I: Included 40 patients with endometrial cancer.

- Category II: Included 60 patients with benign diseases affecting the endometrium. These were subdivided into two groups of patients:

1- Group A: Included 41 patients with endometrial diseases which were classified into (15 patients with endometrial hyperplasia, 14 patients with endometrial polyps, 6 patients with endometritis and 6 patients with molar pregnancy).

2- Group B: Included 19 patients with subendometrial diseases which were classified into (1 1 patients with ordinary leiomyomas, 3 patients with cellular leiomyomas and 5 patients with focal adenomyomas).

The most affected age group in patients with endometrial cancer was 60-70 years in $18 / 40$ patients, as regard benign endometrial and suben- dometrial diseases the most affected age group was $40-50$ years in 20/60 patients. The mean age \pm standard deviation of 40 patients with endometrial cancer $(60.23 \pm 8.07)$ was significantly higher than that of 60 patients with benign diseases affecting the endometrium $(48.67 \pm 14.65)$ with $p$-value $<0.001$.

Abnormal vaginal bleeding was the most common clinical presentation among our patients, as it was seen in $96 / 100$ patients. Other clinical presentations include: Pelvic pain in $27 / 100$ patients, pelvi abdominal enlargement in 18/100 patients, vaginal discharge in $3 / 100$ patients, dysmenorrhea in $2 / 100$ patients and infertility in $1 / 100$ patients.

\section{Category I: Endometrial cancer:}

The details of the histopathological findings were summarized in (Table 1).

Table (1): The final pathological diagnosis among the 40 cases with endometrial cancer.

\begin{tabular}{lll}
\hline Pathology & $\begin{array}{c}\text { Frequency } \\
(\mathrm{n})\end{array}$ & $\begin{array}{c}\text { Percentage } \\
(\%)\end{array}$ \\
\hline Histopathological subtype: & & \\
- Endometrial carcinoma type I & 34 & 85 \\
- Endometrial carcinoma type II & 6 & 15 \\
- Serous papillary carcinoma & 2 & 5 \\
• Clear cell carcinoma & 1 & 2.5 \\
• Carcinosarcoma & 1 & 2.5 \\
• Large cell neuroendocrine & 1 & 2.5 \\
$\quad$ carcinoma & & \\
- Undifferentiated carcinoma & 1 & 2.5 \\
& & \\
Histological grade: & 10 & 25 \\
- Grade 1 & 15 & 37.5 \\
- Grade 2 & 15 & 37.5 \\
- Grade 3 & & \\
FIGO staging: & 11 & 27.5 \\
- IA & 6 & 15 \\
- IB & 14 & 35 \\
- IIIC & 2 & 5 \\
- IVA & 7 & 17.5 \\
- IVB & & \\
\hline
\end{tabular}

\section{Conventional MRI findings:}

As regard T1-WI: 37/40 cases showed isointense SI and 3/40 cases showed heterogeneous SI. While; in T2-WI: 37/40 cases showed hypointense SI and 3/40 cases showed heterogeneous SI, if compared with normal endometrium. As regard study of early post contrast enhancement pattern: $33 / 40$ cases showed weak enhancement, $5 / 40$ cases showed moderate enhancement and 2/40 cases showed strong enhancement if compared to normal myometrial enhancement.

As regard myometrial invasion: $25 / 40$ cases showed deep myometrial invasion, 9/40 cases 
showed superficial myometrial invasion and 6/40 showed intact endometrial-myometrial interface.

\section{WI-MRI findings:}

All studied cases with endometrial cancer displayed high signal at DW images at (high $b$ value $1000 \mathrm{~s} / \mathrm{mm}^{2}$ ) corresponding to low ADC values with restricted pattern at the ADC map. The mean $\mathrm{ADC}$ value was found about $0.73 \pm 0.1 \times 10^{-3} \mathrm{~mm} / \mathrm{s}$.

Category II: Benign diseases affecting the endometrium:

1-Group (A): Endometrial diseases:

a-Endometrial hyperplasia:

The final histopathological results were simple hyperplasia without atypia in $12 / 15$ patients and complex hyperplasia without atypia in $3 / 15$ patients.

\section{Conventional MRI findings:}

As regard T1-WI: 14/15 cases showed isointense SI and $1 / 15$ cases showed hypointense SI. While; in T2-WI: 8/15 cases showed heterogeneous SI, 5/15 cases showed isointense SI and 2/15 cases showed hypointense SI if compared with normal endometrium. As regard study of early post contrast enhancement pattern: 13/15 cases showed moderate enhancement and 2/15 cases showed strong enhancement if compared to normal myometrial enhancement.

Junctional zone is intact in $13 / 15$ cases, however; it is interrupted in $2 / 15$ cases due to coexistence of adenomyosis.

\section{WI-MRI findings:}

Endometrial hyperplasia displayed high signal at DW images at (high b value $1000 \mathrm{~s} / \mathrm{mm}^{2}$ ) which correspond to high ADC values with non restricted pattern at the ADC map in 14/15 cases and low signal at DW images corresponding to high ADC values with free diffusion pattern at the ADC maps in $1 / 15$ case due to cystic changes. The mean ADC value was found about $1.42 \pm 0.1 \times 10^{-3} \mathrm{~mm}^{2} / \mathrm{s}$.

\section{b- Endometrial polyp: \\ Conventional MRI findings:}

As regard T1-WI: 8/14 cases showed isointense SI and 6/14 cases showed heterogeneous SI. While; in T2-WI: 7/14 cases showed heterogeneous SI, 6/14 cases showed hypointense SI and 1/14 case showed isointense SI if compared with normal endometrium. As regard study of early post contrast enhancement pattern: 8/14 cases showed strong enhancement and 6/14 cases showed moderate enhancement if compared to normal myometrial enhancement.
Specific findings were noted: T2-WI low SI fibrous core in 11/14 cases, T2-WI high SI intratumoral cysts in 10/14 cases and hemorrhage in $6 / 14$ cases.

Endometrial-myometrial interface is intact in $11 / 14$ cases, however; it is illdefined in $3 / 14$ cases due to coexistence of adenomyosis in one case and large polypoidal mass thinning out the myometrium in two cases.

\section{DWI-MRI findings:}

Endometrial polyps displayed low signal at DW images at (high $b$ value $1000 \mathrm{~s} / \mathrm{mm}^{2}$ ) which correspond to high ADC values with free diffusion pattern at the ADC map in 7/14 cases and intermediate signal at DW images corresponding to high $\mathrm{ADC}$ values with non restricted pattern at the ADC map in 7/14 cases. The mean ADC value was found about $1.51 \pm 0.10 \times 10^{-3} \mathrm{~mm}^{2} / \mathrm{s}$.

\section{c- Endometritis:}

\section{Conventional MRI findings:}

As regard T1-WI: 3/6 cases showed isointense SI and 3/6 cases showed heterogeneous SI. While; in T2-WI: 3/6 cases showed heterogeneous SI, 3/6 cases showed hypointense SI if compared with normal endometrium. As regard study of early post contrast enhancement pattern: $6 / 6$ cases showed peripheral strong enhancement if compared to normal myometrial enhancement.

Concurrent pathologies were seen: Pelvic inflammatory disease in $3 / 6$ cases, retained product of conception in $2 / 6$ cases cancer cervix in $1 / 6$ case.

All studied cases showed intact endometrialmyometrial interface.

\section{DWI-MRI findings:}

All studied cases with endometritis displayed high signal at DW images at (high $b$ value 1000s/ $\mathrm{mm}^{2}$ ) corresponding to low ADC values with restricted pattern at the ADC map. The mean ADC value was found about $0.82 \pm 0.09 \times 10^{-3} \mathrm{~mm}^{2} / \mathrm{s}$.

\section{$d$ - Gestational trophoplastic disease:}

The final histopathological results were non invasive complete mole in 3/6 patients, invasive complete mole in $2 / 6$ patients and non invasive partial mole in $1 / 6$ patient.

\section{Conventional MRI findings:}

As regard T1-WI: $6 / 6$ cases showed heterogeneous low SI. While; in T2-WI: 6/6 cases showed heterogeneous high SI if compared with normal 
endometrium. As regard study of early post contrast enhancement pattern: $5 / 6$ showed heterogeneous strong enhancement and 1/6 showed heterogeneous moderate enhancement if compared to normal myometrial enhancement.

All studied cases showed distended uterus with characteristic heterogeneous snow storm appearance cystic like spaces with loss of uterine zonal anatomy.

Specific findings were noted: Focal myometrial contractions in $4 / 6$ cases, hemorrhage in $6 / 6$ cases, intramyometrial vessels in $6 / 6$ cases and theca lutein cysts in $3 / 6$ cases.

\section{DWI-MRI findings:}

All studied cases with molar pregnancy displayed low signal at DW images at (high $b$ value $1000 \mathrm{~s} / \mathrm{mm}^{2}$ ) corresponding to high ADC values with free diffusion pattern at the ADC map. The mean ADC value was found about $1.75 \pm 0.05$ X10 $3 \mathrm{~mm}^{2} / \mathrm{s}$.

\section{2- Group (B): Subendometrial diseases:}

a- Ordinary leiomyoma:

\section{Conventional MRI findings:}

As regard T1-WI: 8/11 cases showed isointense SI and 2/11 showed heterogeneous SI and 1/11 showed hyperintense SI. While; in T2-WI: 7/11 cases showed hypointense SI, 2/11 cases showed isointense SI and 2/11 cases showed heterogeneous SI if compared with normal myometrium. As regard study of early post contrast enhancement pattern: 9/11 showed weak enhancement and 2/11 showed no enhancement if compared to normal myometrial enhancement.

\section{DWI-MRI findings:}

Ordinary leiomyomas displayed low in $6 / 11$ to intermediate signals in 5/11 cases at DW images at (high $b$ value $1000 \mathrm{~s} / \mathrm{mm}^{2}$ ) showing no significant reduction in $\mathrm{ADC}$ values with relative non restricted pattern at the ADC map. The mean $\mathrm{ADC}$ value was found about $1.37 \pm 0.11 \times 10^{-3} \mathrm{~mm}^{2} / \mathrm{s}$.

\section{b- Cellular leiomyoma:}

\section{Conventional MRI findings:}

As regard T1-WI: $3 / 3$ cases showed isointense SI. While; in T2-WI: $2 / 3$ cases showed hyperintense SI, $1 / 3$ cases showed isointense if compared with normal myometrium. As regard study of early post contrast enhancement pattern: $3 / 3$ showed moderate enhancement.

\section{DWI-MRI findings:}

All studied cases with cellular leiomyomas displayed high signal at DW images at (high $b$ value $1000 \mathrm{~s} / \mathrm{mm} 2$ ) corresponding to low ADC values with restricted pattern at the ADC map. The mean ADC value was found about $0.9 \pm 0.05 \mathrm{X}$ $10^{-3} \mathrm{~mm}^{2} / \mathrm{s}$.

\section{c-Focal adenomyoma:}

\section{Conventional MRI findings:}

As regard T1-WI: $3 / 5$ cases showed isointense SI and $2 / 5$ cases showed heterogeneous SI. While; in T2-WI: 2/5 cases showed hypointense SI, 2/5 cases showed heterogeneous SI and $1 / 5$ case showed isointense SI if compared with normal myometrium. As regard study of early post contrast enhancement pattern: $4 / 5$ cases showed moderate enhancement and 1/5 case showed weak enhancement.

\section{DWI-MRI findings:}

All studied cases with focal adenomyomas displayed intermediate signal at DW images at (high $b$ value $1000 \mathrm{~s} / \mathrm{mm}^{2}$ ) showing no prominent decrease of ADC values with relative non restricted pattern at the ADC map. The mean ADC value was found about $1.2 \pm 0.02 \times 10^{-3} \mathrm{~mm}^{2} / \mathrm{s}$.

Table (2): Comparison between the mean ADC value among the 60 studied cases with benign diseases affecting the endometrium.

\begin{tabular}{lll}
\hline Benign diseases & $\begin{array}{c}\text { ADC X10 } \\
\text { Mean } \pm \mathrm{mD}\end{array}{ }^{2} / \mathrm{s}$ & $\begin{array}{c}\text { Test of } \\
\text { significance }\end{array}$ \\
\hline Endometrial hyperplasia & $1.416 \pm 0.1^{\mathbf{a}}$ & $\mathrm{F}=44.4$ \\
Endometrial Polyp & $1.5121 \pm 0.10$ & $p<0.001^{*}$ \\
Endometritis & $0.82 \pm 0.08 \mathbf{b}$ & \\
Molar pregnancy & $1.75 \pm 0.05$ & \\
Ordinary leiomyoma & $1.37 \pm 0.11 \mathbf{a}$ & \\
Cellular leiomyoma & $0.90 \pm 0.06 \mathbf{b}$ & \\
Focal adenomyoma & $1.2 \pm 0.02$ &
\end{tabular}

\begin{tabular}{ll}
\hline Total & $1.36 \pm 0.32$ \\
\hline
\end{tabular}

F: One Way ANOVA test.

* Statistically significant $(p<0.05)$

- Similar superscripted letters in the same column denote non significant statistical differences between groups.

The overall difference $(p<0.001)$ and the difference between each group of benign endometrial and subendometrial pathologies mean ADC values was significant, however; the difference between the mean ADC values of endometrial hyperplasia and ordinary leiomyomas $(p=0.58)$ as well as that of endometritis and cellular leiomyomas were insignificant $(p=0.29)$. 
Table (3): Comparison of DWI SI (at high $b$ value $1000 \mathrm{~s} / \mathrm{mm}^{2}$ ) between 40 studied patients with endometrial cancer and 60 studied group with benign diseases.

\begin{tabular}{|c|c|c|c|}
\hline & $\begin{array}{l}\text { Endometrial } \\
\text { cancer }\end{array}$ & $\begin{array}{l}\text { Benign } \\
\text { diseases }\end{array}$ & $\begin{array}{c}\text { Test of } \\
\text { significance }\end{array}$ \\
\hline \multirow{2}{*}{\multicolumn{4}{|c|}{$\begin{array}{l}\text { DWI_SI (at high b value } \\
\left.1000 \mathrm{~s} / \mathrm{mm}^{2}\right):\end{array}$}} \\
\hline & & & \\
\hline \multicolumn{4}{|c|}{ Low: } \\
\hline $\mathrm{n}$ & 0 & 21 & $\mathrm{MC}$ \\
\hline$\%$ & $0 \%$ & $35 \%$ & $p<0.001 *$ \\
\hline \multicolumn{4}{|c|}{ Intermediate: } \\
\hline $\mathrm{n}$ & 0 & 16 & \\
\hline$\%$ & $0 \%$ & $26.7 \%$ & \\
\hline \multicolumn{4}{|c|}{ High: } \\
\hline $\mathrm{n}$ & 40 & 23 & \\
\hline$\%$ & $100 \%$ & $38.3 \%$ & \\
\hline
\end{tabular}

MC: Monte-Carlo test. $\quad *$ Statistically significant $(p<0.05)$.

All studied patients with endometrial cancer had a tendency to demonstrate high signal on DWI at high $b$ value $1000 \mathrm{~s} / \mathrm{mm}^{2}$, while benign diseases showed variable appearance including low, intermediate and high signals with high significant difference $(p<0.001)$.

Table (4): Comparison of the mean ADC value between 40 studied patients with endometrial cancer and 60 studied patients with benign diseases.

\begin{tabular}{llll}
\hline & $\begin{array}{c}\text { Endometrial } \\
\text { cancer } \\
\mathrm{N}=40\end{array}$ & $\begin{array}{c}\text { Benign } \\
\text { diseases } \\
\mathrm{N}=60\end{array}$ & $\begin{array}{c}\text { Test of } \\
\text { significance }\end{array}$ \\
\hline $\begin{array}{llll}\text { ADCx } 10-3 \mathrm{~mm} 2 / \mathrm{s} \\
\text { Mean } \pm \mathrm{SD}\end{array}$ & $0.73 \pm 0.10$ & $1.36 \pm 0.32$ & $t=13.87$ \\
$\begin{array}{l}\text { Median } \\
\text { (range) }\end{array}$ & 0.73 & 1.39 & $p<0.001^{*}$ \\
\hline$t$ Student t test. & * Statistically significant $(p<0.05)$.
\end{tabular}

The mean ADC value of endometrial cancer was $0.73 \pm 0.10 \times 10^{-3} \mathrm{~mm}^{2} / \mathrm{s}$ and for benign diseases, it was $1.36 \pm 0.32 \times 10^{-3} \mathrm{~mm}^{2} / \mathrm{s}$ which was significantly higher than that of endometrial cancer with $p$-value $<0.001$ (Fig. 1).

Fig. (1): Box and Whisker plots demonstrating ADC values of endometrial cancer and benign endometrial diseases. The center horizontal line indicates the median value. The bottom and top edges of the box indicate the 25 th and 75 th percentiles. The vertical line indicates the range of data.

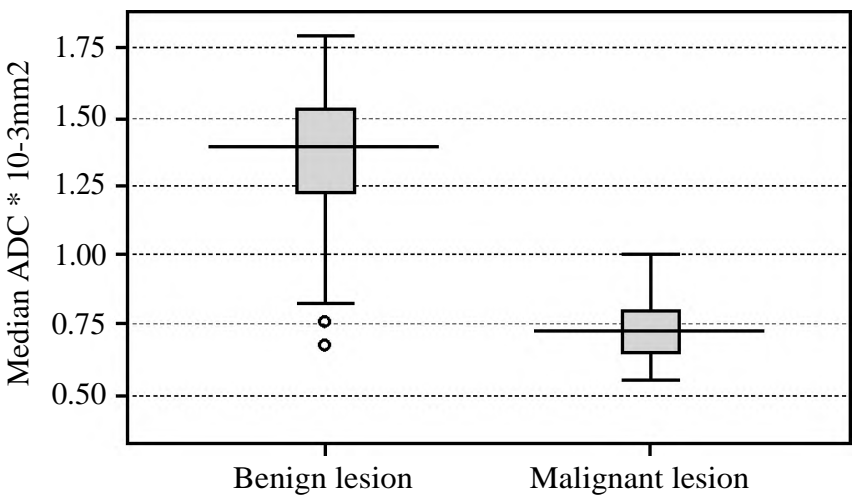

Table (5): The valididity of mean ADC value in differentiation between endometrial cancer and benign diseases affecting the endometrium.

\begin{tabular}{lccccccc}
\hline & $\begin{array}{c}\text { AUC } \\
(95 \% \mathrm{CI})\end{array}$ & $\begin{array}{c}\text { Cut off } \\
\text { point }\end{array}$ & $\begin{array}{c}\text { Sensitivity } \\
(\%)\end{array}$ & $\begin{array}{c}\text { Specificity } \\
(\%)\end{array}$ & $\begin{array}{c}\text { PPV } \\
(\%)\end{array}$ & $\begin{array}{c}\text { NPV } \\
(\%)\end{array}$ & $\begin{array}{c}\text { Accuracy } \\
(\%)\end{array}$ \\
\hline ADC value & 0.97 & $\leq 0.915$ & $97.5 \%$ & $88.3 \%$ & $84.8 \%$ & $98.1 \%$ & $92.0 \%$ \\
$\mathrm{X} 10^{-3} \mathrm{~mm}^{2} / \mathrm{s}$ & $(0.95-1.0)$ & & & & & & \\
\hline
\end{tabular}

AUC: Area Under Curve. PPV: Positive predictive value. NPV: Negative predictive value.

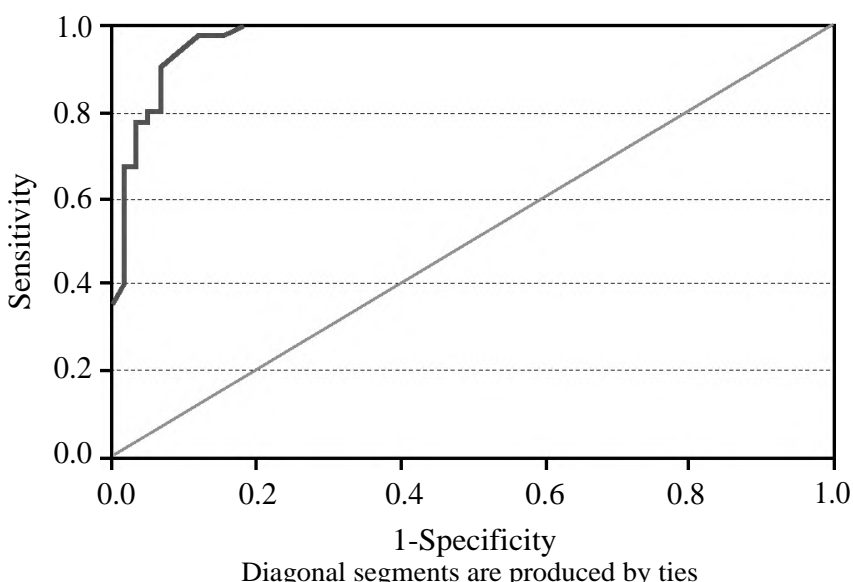

Fig. (2): ROC curve showing the validity of mean ADC in differentiation between endometrial cancer and benign diseases. The area under the (ROC) curve was 0.97 . A cut off value of $0.915 \times 10^{-3} \mathrm{~mm}^{2} / \mathrm{s}$ was considered to be the threshold. When an ADC value of $0.97 \times 10^{-3} \mathrm{~mm}^{2} / \mathrm{s}$ or more was estimated the lesion was considered to be benign and a value below the threshold was considered to indicate endometrial cancer with the sensitivity, specificity and accuracy of $97.5 \%, 88.3 \%$ and $92.0 \%$ respectively. 

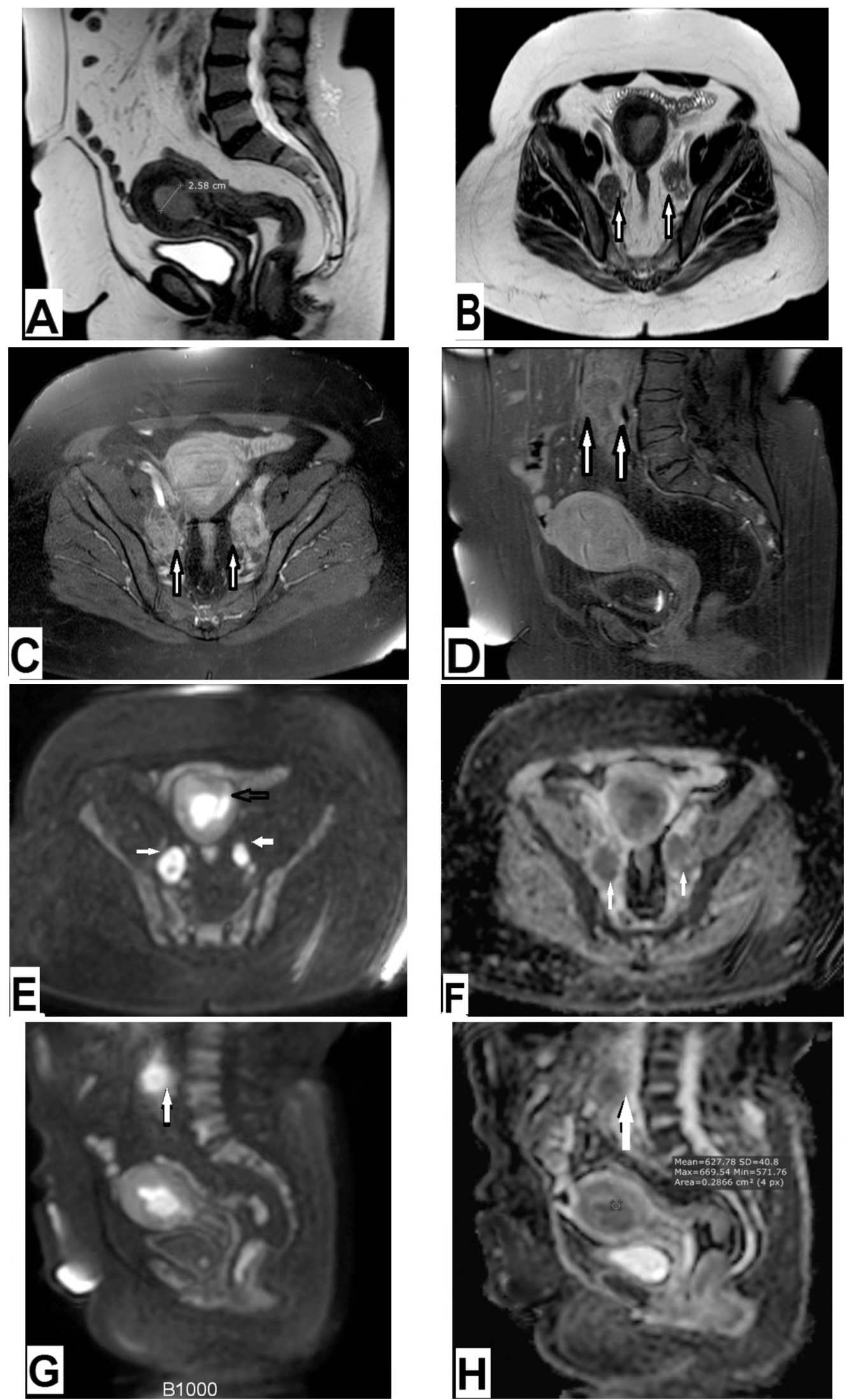

Case (1): Pathologically proven grade 3 endometrioid adenocarcinona. Figs. (A) Sagittal. (B) Axial T2-WI showed low SI endometrial mass and bilateral enlarged pelvic lymph nodes (white arrows). (C) Axial. (D) Sagittal post contrast T1 fat suppressed images demonstrated weak enhancement of the lesion and heterogeneous enhancement of regional and retroperitoneal lymph nodes (white arrows). (E) Axial, (G) sagittal DWI $\left(b=1000 \mathrm{~s} / \mathrm{mm}^{2}\right)$ showed deep myometrial invasion (black arrow) (F) axial, (H) sagittal ADC map showed restricted diffusion pattern of the mass. The ADC value was measured $=0.63 \times 10^{-3} \mathrm{~mm}^{2} / \mathrm{s}$, bilateral enlarged local pelvic lymph nodes in (E,F) and retroperitoneal enlarged lymph node in $(\mathrm{G}, \mathrm{H})$ displaying high SI at DWI and low SI at ADC maps similar to the primary tumor (white arrows). 

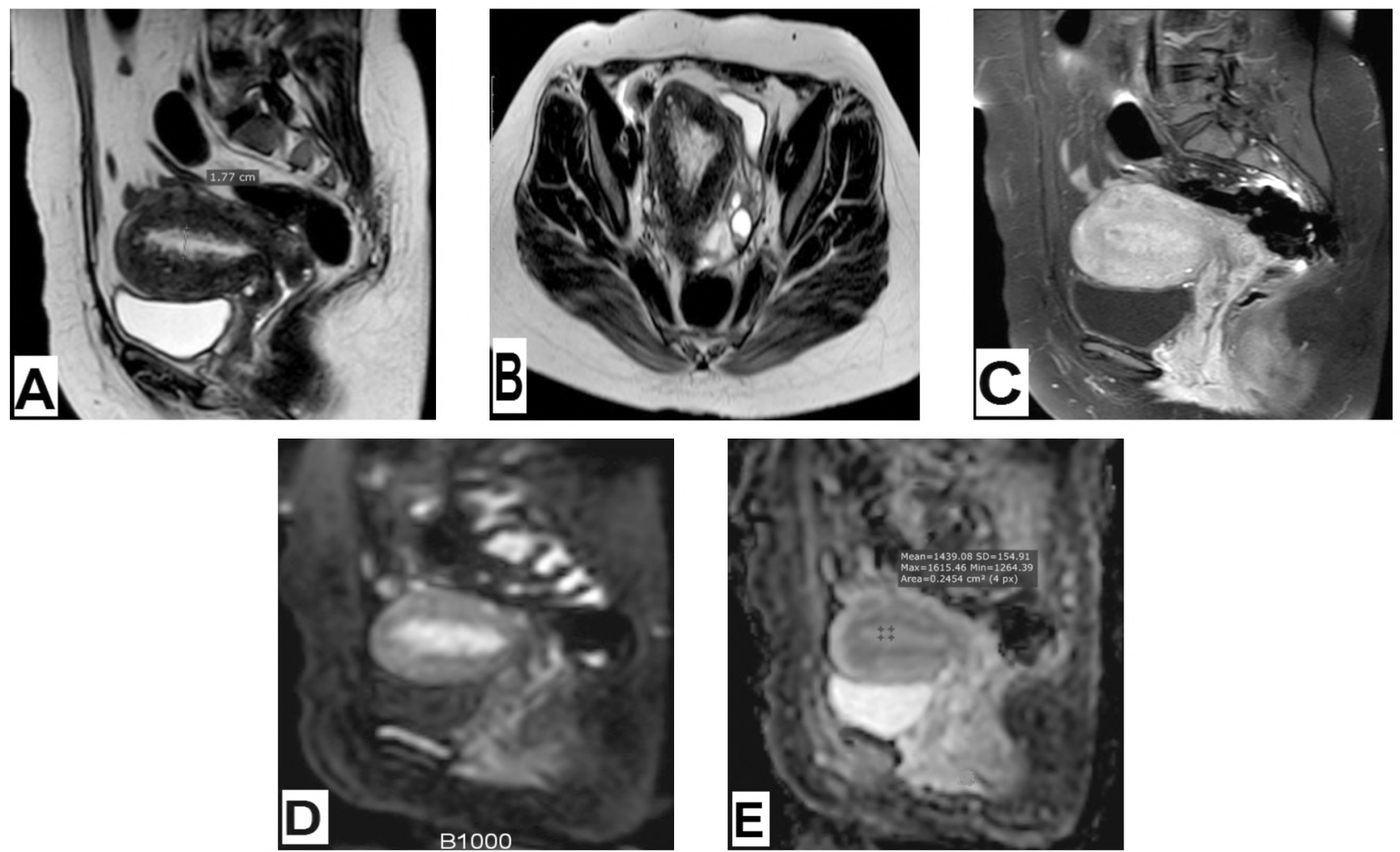

Case (2): Pathologically proven simple endometrial hyperplasia without atypia. Figs. (A) Sagittal (B) Axial T2-WIs showed diffuse endometrial thickening displaying heterogeneous SI with picture of adenomyotic changes in the form of irregular endometrial-myometrial junction, thickened junctional zone and high SI linear striation on T2-WI extending from the endometrium into the myometrium with subsequental pseudowidening of the endometrium. (C) Sagittal post contrast T1-W fat suppressed image shows global enhancement following the normal endometrium. (D) Sagittal DWI ( $b=1000 \mathrm{~s} / \mathrm{mm}$ ) shows high SI within the endometrium, with corresponding high SI at (E) Sagittal ADC map denoting non restricted diffusion pattern. The ADC value was measured $=1.44 \times 10^{-3} \mathrm{~mm} / \mathrm{s}$.
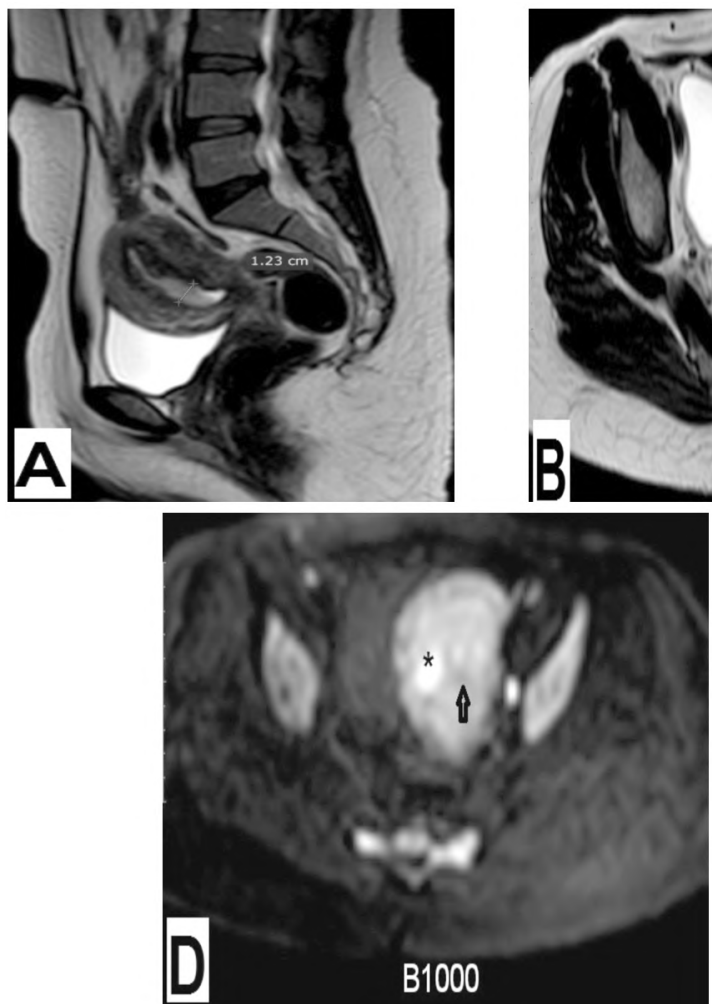
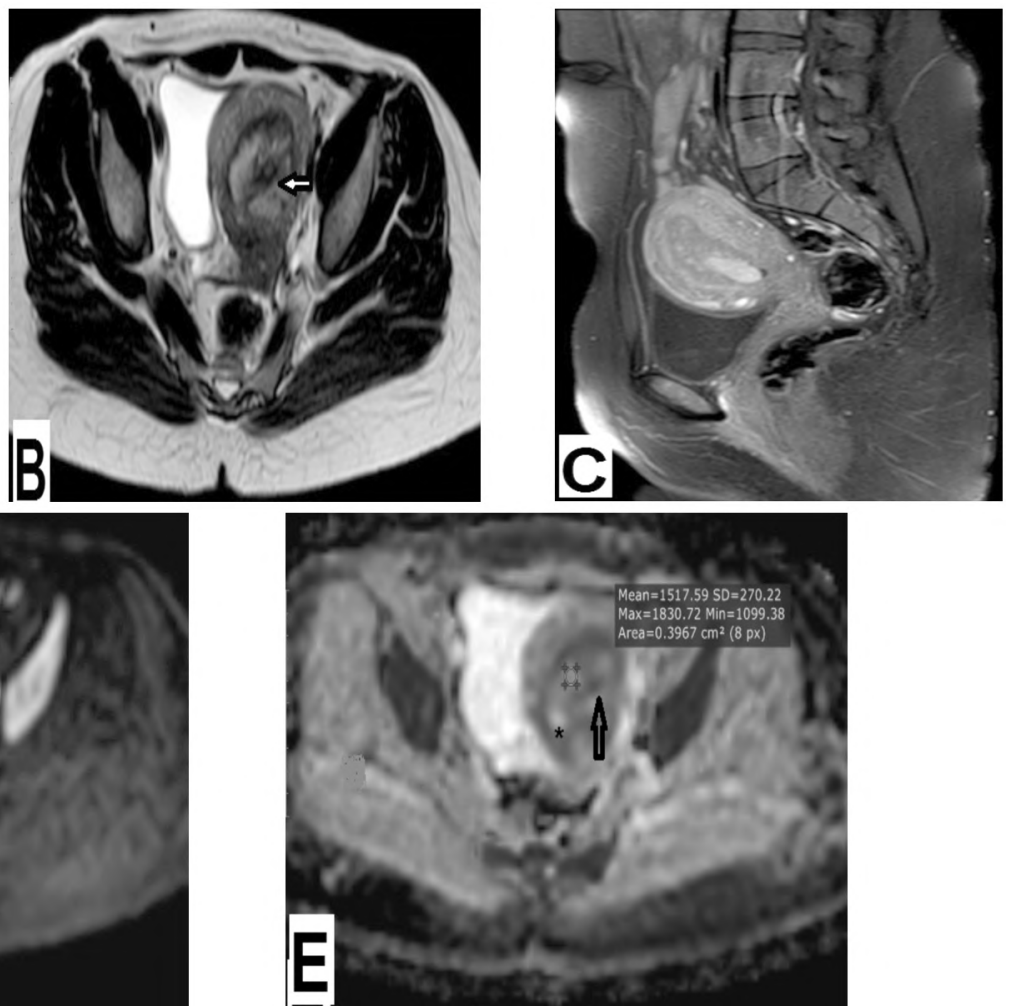

Case (3): Pathologically proven endometrial polyp. Figs. (A) Sagittal T2-WI shows focal endometrial thickening displaying heterogeneous SI with hypointense linear SI component suggesting fibrous core (white arrow) at (B) axial T2-WI with intact endometrial junctional zone interface. (C) Sagittal post contrast T1-W fat suppressed image shows avid strong partial enhancement. Axial DWI $(b=1000 \mathrm{~s} / \mathrm{mm})$ the lesion displaying intermediate SI, corresponding to high SI at (E) Axial ADC map denoting non restricted diffusion pattern. The ADC value was found $1.52 \times 10 \mathrm{~mm} / \mathrm{s}$. N.B: [Low SI fibrous core on DWI and ADC map (black arrow), also small intratumoral cyst displaying T2 shine through effect in the form high SI on both DWI and ADC map (black asterisk) are noted]. 

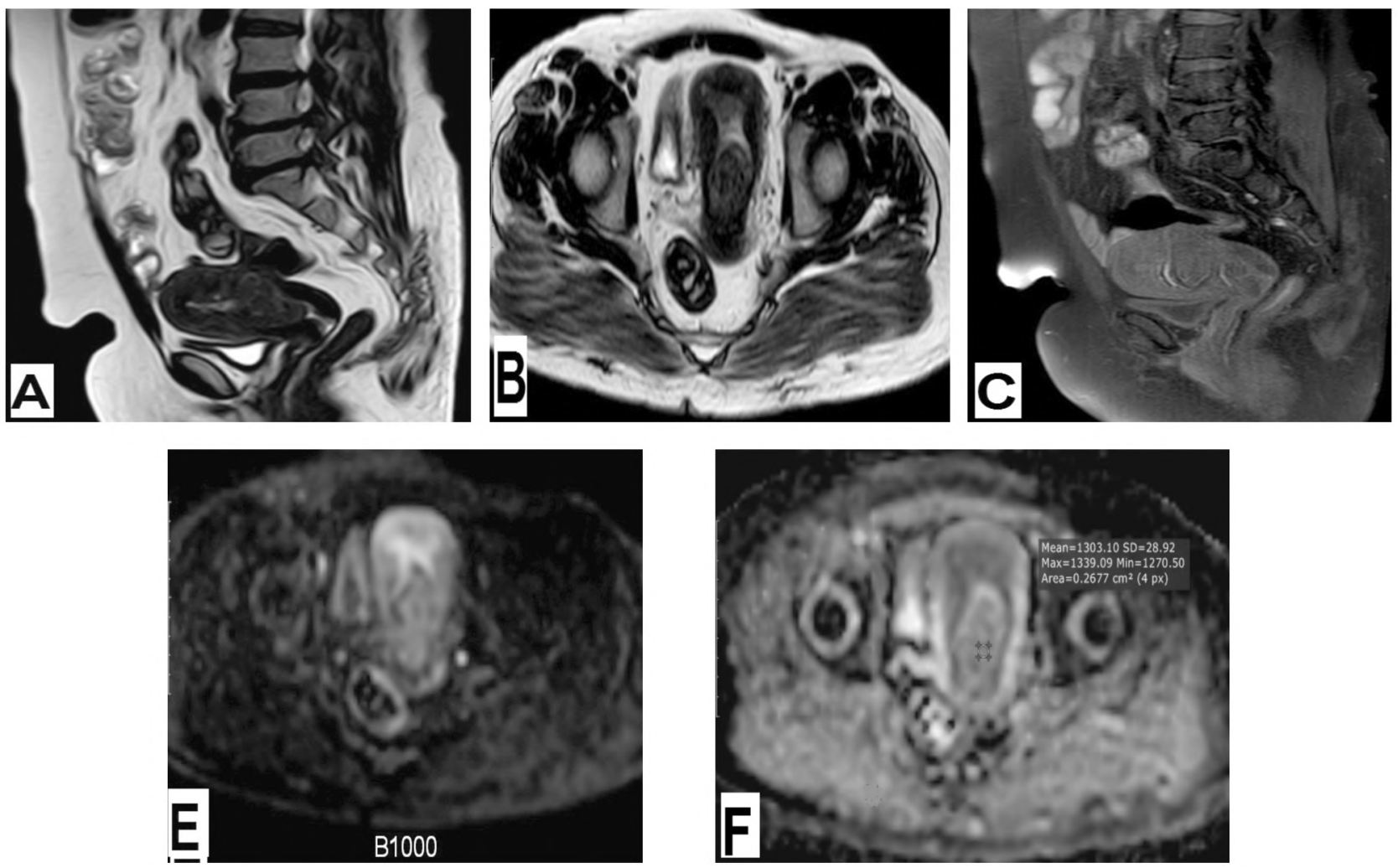

Case (4): Pathologically proven submucosal uterine fibroid. Figs. (A) Sagittal T2-WI (B) axial T2-WI showing a well defined isointense mass compared to the myometrium involving the lower part of the endometrial cavity, the related posterior wall of the myometrium and extending into the endocervical canal through a dilated internal os.(C) Sagittal post contrast T1-W fat suppressed image showed weak enhancement of the mass. (D) Axial DWI ( $b=1000 \mathrm{~s} / \mathrm{mm}^{2}$ ) shows the mass displaying intermediate $\mathrm{SI}_{3}$ with no significant reduction of SI at (E) Axial ADC map denoting non restriced diffusion pattern. The ADC value was measured $=1.30 \times 10^{-3} \mathrm{~mm} 2 / \mathrm{s}^{\text {. }}$
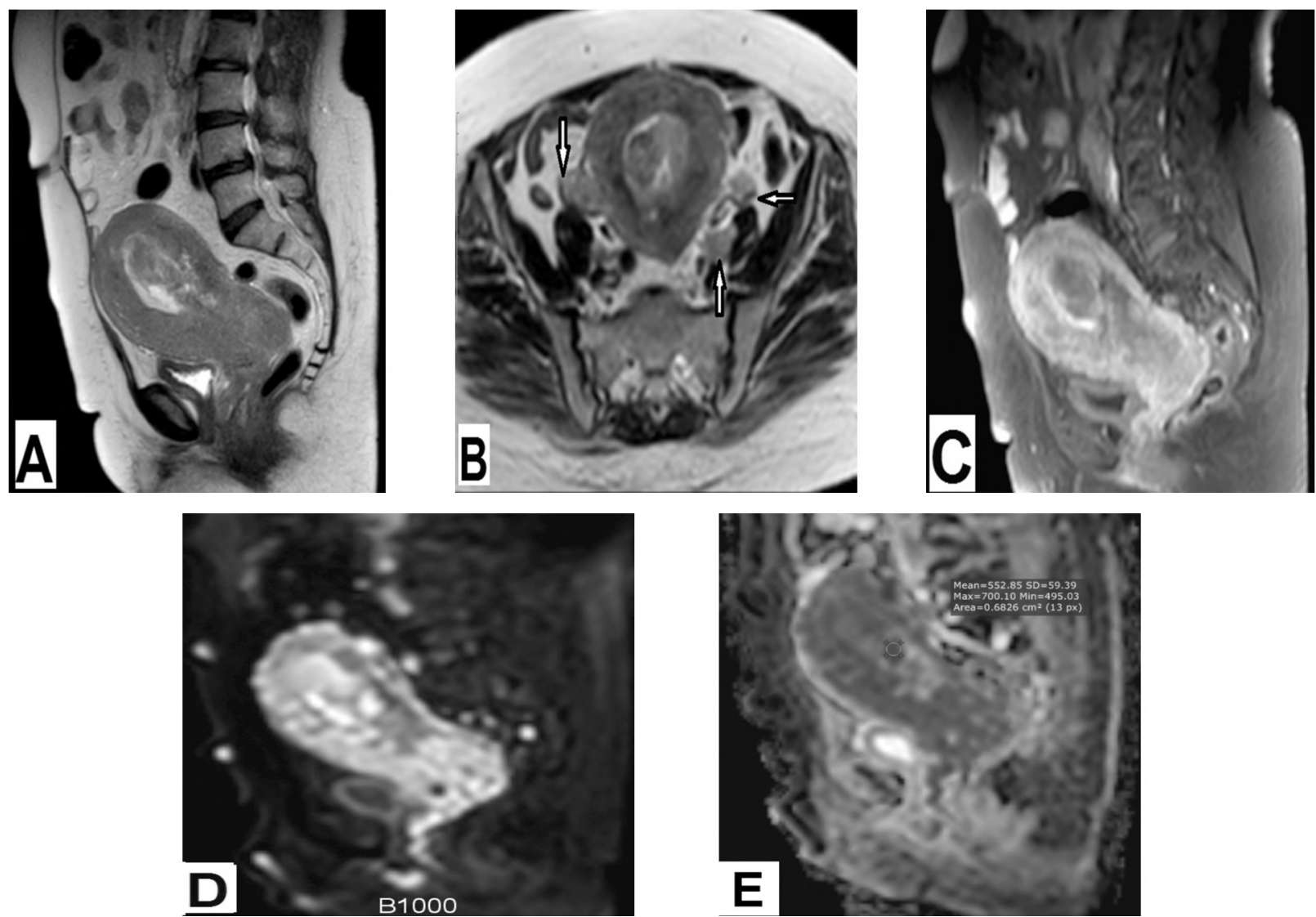

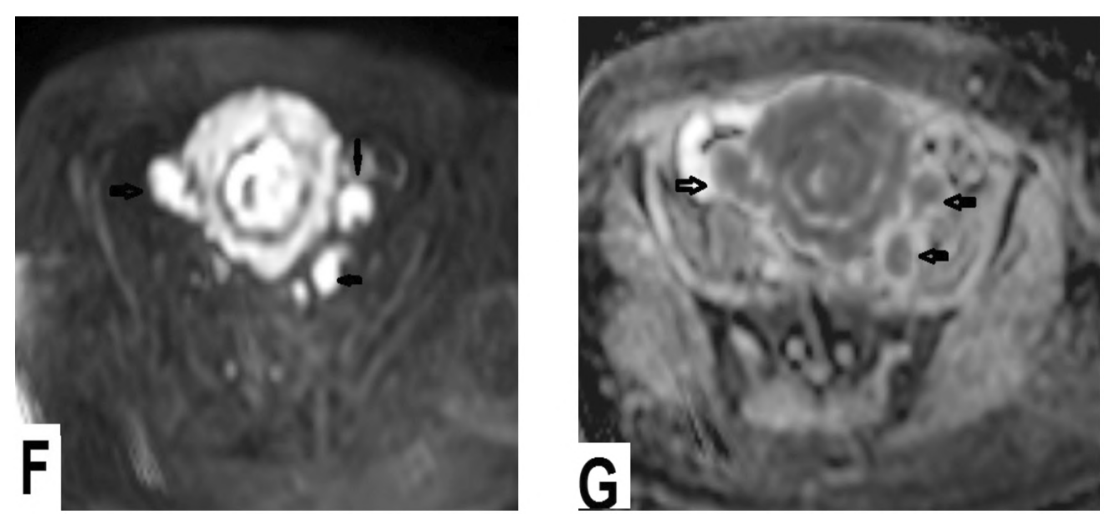

Case (5): Pathologically proven high grade non endometrioid adenocarcinoma (small cell neuroendocrine carcinoma). Figs. (A) Sagittal T2-WI demonstrated bulky uterus with an endometrial polypoidal mass of heterogeneous SI (B) Axial T2-WI showed bilateral enlarged pelvic lymph nodes. (C) Sagittal T1-W fat suppressed image shows heterogeneous enhancement. (D) Sagittal DWI $\left(b=1000 \mathrm{~s} / \mathrm{mm}^{2}\right.$ ) (E) Sagittal ADC map showed infilterating tumor diffusely involving the myometrium, the cervix and the vagina with restricted diffusion pattern. The ADC value was measured $=0.55 \times 10^{-3} \mathrm{~mm}^{2} / \mathrm{s}$. (F) Axial DWI bilateral enlarged pelvic lymph nodes (black arrows) showed high SI and low SI at (G) axial ADC map similar to the primary tumor.

\section{Discussion}

We investigated the diagnostic efficacy of DWI and ADC values in 100 female patients with endometrial and subendometrial pathologies, their ages ranged from 20-85 years, presented with abnormal vaginal bleeding in $(96 \%)$ of studied cases and how can DWI and the mean ADC values provide a diagnostic differentiation between endometrial carcinoma and benign endometrial diseases.

Endometrial cancer occurs most frequently in women during the sixth and seventh decades of life [7], our study revealed statistically significant difference between the age group having endometrial cancer (mean age \pm SD $60.23 \pm 8.07$ ) and those having benign endometrial diseases (mean age \pm SD $48.67 \pm 14.65$ ), so endometrial cancer affected older age group. This was in agreement with study conducted by Bakir et al., [10].

In this current study, morphological MRI signal intensities were not significantly different in discrimination between malignant and benign diseases affecting the endometrium this was matched with the results of the study performed by Kierans et al., [11]. We found different pathological types of endometrial and subendometrial diseases with variable appearance on DWI and ADC map.

Our study revealed that all studied cases with endometrial carcinoma were more likely to have restricted diffusion due to high cellularity in the form of high signal on high $b$-value $\left(1000 \mathrm{~s} / \mathrm{mm}^{2}\right)$ DWI and low ADC value $\left(0.73 \pm 0.1 \times 10^{-3} \mathrm{~mm}^{2} / \mathrm{s}\right)$ this was almost similar to the results of study performed by Shady, et al., [12] .
Addley et al., [13] stated that not all lesions with restricted diffusion on DWI are malignant, and there are many benign diseases can exhibit restricted diffusion pattern, this clarifies the importance of the use of DWI as an adjunct rather than a replacement for morhological imaging sequences in lesion characterization. We had (9) pathologically proved benign diseases with restricted diffusion pattern included (3) cellular leiomyomas and (6) endometritis.

According to Duarte et al., [14] the presence of restricted diffusion within cellular leiomyomas due to their characteristic high cellularity, so image analysis should always be made in correlation with the appearances on T1 and T2 WI. In endometritis, the presence of pus which is a fluid with high viscosity and dense cellularity can explain the high SI in DWI and the low ADC value, after contrast study, the pus shows abscent enhancement, which can be easily differentiated from malignant tumors with enhanced solid parts.

In DW imaging qualitative analysis, we found that the majority of endometrial hyperplasia exhibited high SI and only one case displayed low SI due to cystic changes secondary to tamoxifen therapy this was matched with Bakir et al., [10] and Ahmed et al., [15] who observed that qualitative analysis of diffusion image alone cannot distinguish endometrial lesions so quantitative analysis with the ADC map is fundamental for endometrial lesions characterization. We found that mean ADC value for endometrial hyperplasia was $(1.42 \pm 0.1$ $\times 10^{-3} \mathrm{~mm}^{2} / \mathrm{s}$ ) this was in accordance with results of study performed by Elsammak et al., [2]. The high ADC value observed in endometrial hyperplasia can be explained by prominant extracellular 
area with edematous tissue and cystic structures [16].

Our study showed that there was high frequency of low SI T2-WI fibrous core and high SI T2-WI intratumoral cystic changes that can be seen by conventional MRI in endometrial polyps which reflect their internal structure, as also stated with Wang et al., [3].

We found in the current study that the signal intensity of endometrial polyps in qualitative analysis of DW imaging was intermediate or low SI this was matched with results obtained by Wang et al., [1] and Ahmed et al., [15] studies. We found also that the mean ADC value was $(1.51 \pm 0.10 \mathrm{x}$ $10^{-3} \mathrm{~mm}^{2} / \mathrm{s}$ ) this was in accordance with results of study performed by Bakir et al., [10] who explained the high ADC value in endometrial polyps due to their histopathologic composition of dense fibrous stroma or smooth muscle, with cystic hyperplasia of endometrial glands, may cause decreased cellular density.

In our study, we found that there was a significant statistical difference between mean ADC value between endometrial polyps and endometrial hyperplasia, in contrast to the results of the study performed by Elsammak et al., [2] . It may be due to avoidance of hemorrhagic regions and the fibrous core in the current study, instead of selecting the largest ROI within the lesion in ADC map.

The current study revealed that the signal intensity of submucosal ordinary leiomyomas in qualitative analysis of DW imaging was intermediate or low SI this was matched with Ahmed et al., [15] \& Sato et al., [17] studies and we found that the mean ADC value was $\left(1.37 \pm 0.10 \times 10^{-3}\right.$ $\mathrm{mm}^{2} / \mathrm{s}$ ) this was in accordance with results of study performed by Elsammak et al., [2] .

We also found that the mean ADC value for endometrial polyps was significantly higher than that for submucosal ordinary leiomyomas this in agreement with Karakas, et al., [9] who stated that leiomyomas can show variable histopathologic features in association with degeneration such as hyalinization and edema. Hyaline changes lead to homogenous eosinophilic strips accumulation in the extracellular area, and the extracellular space narrows. Thus, this histological feature decreases ADC values; however, edema causes increased ADC values due to extracellular space widening.

As regard cellular leiomyomas, we found that its mean ADC value was $\left(0.9 \pm 0.05 \times 10^{-3} \mathrm{~mm}^{2} / \mathrm{s}\right)$, Arlea et al., [18] reported that a value less than 1.1 categorized the lesion in a high-risk group, an ADC value of 1.1 or higher put the lesion as low-risk group.

Although MRI is often able to differentiate between submucosal endometrial lesions including focal adenomyoma and leiomyomas, sometimes their imaging features may overlap [19]. In the qualitative analysis of DW imaging, we found that focal adenomyoma exhibited intermediate SI this was matched with study performed by Takeuchi and Matsuzaki, [20]. We found that the mean ADC value was $\left(1.2 \pm 0.02 \times 10^{-3} \mathrm{~mm}^{2} / \mathrm{s}\right)$ this was in accordance with results of study performed by Kilickesmez et al., [21]. We found also that the mean ADC value is significantly lower than fibroids similar to the results of previous studies performed by Tian et al., [22], Jha et al., [19] and Kilickesmez et al., [21].

Another benign endometrial disease that we have investigated in our study is gestational trophoplastic disease (GTD). Lima et al., [23] stated that diagnosis of GTD should depend on a clinical history, physical examination, serum B-HCG level and pelvic ultrasound. The evaluation of GTD does not include MRI routinely, which is recommended in complicated and suspicious cases. We found in our study that GTD had specific radiological findings in conventional MRI included snow storm appearance, tortuous myometrial vessels, focal hemorrhagic areas and myometrial contraction this was in accordance with Sefidbakht et al., [24]. By DWI qualitative analysis all cases displayed low SI with mean ADC value $1.75 \pm 0.05$ which was significantly higher than the other benign endometrial diseases in the current study being vesicular and cystic, if compared to most other tumors, rather than cellular and dense this was in accordance with results of study performed by Sefidbakht et al., [24].

Haldorsen and Salvesen, [25] stated that the mean ADC values of endometrial cancer have been reported to range between $\left(0.75-0.97 \times 10^{-3} \mathrm{~mm}^{2} / \mathrm{s}\right)$ was statistically significant lower than that reported for benign endometrial lesions $\left(1.21-1.76 \times 10^{-3}\right.$ $\mathrm{mm}^{2} / \mathrm{s}$ ) in different studies.

In our study, a significant difference $(p=<0.001)$ was found between the mean ADC values of endometrial cancer $\left(0.73 \pm 0.1 \times 10^{-3} \mathrm{~mm}^{2} / \mathrm{s}\right)$ and benign endometrial diseases $\left(1.36 \pm 0.32 \times 10^{-3} \mathrm{~mm}^{2} / \mathrm{s}\right)$. Using $\left(0.915 \times 10^{-3} \mathrm{~mm}^{2} / \mathrm{s}\right)$ as a cut off value for distinguishing between endometrial cancer and benign endometrial diseases had $97.5 \%$ sensitivity, $88.3 \%$ specificity and $92.0 \%$ accuracy. 
Kececi et al., [26] reported that the mean ADC value of the endometrial cancer $\left(0.94 \pm 0.18 \times 10^{-3}\right.$ $\mathrm{mm}^{2} / \mathrm{s}$ ) was statistically significantly lower than the ADC value of benign lesions ( $1.45 \pm 0.22 \times 10^{-3}$ $\mathrm{mm}^{2} / \mathrm{s}$ ) and the ADC threshold value to determine whether the lesions were benign or malignant was $\left(1.10 \times 10^{-3} \mathrm{~mm}^{2} / \mathrm{s}\right)$ with $85.7 \%$ sensitivity and $92.8 \%$ specificity.

Elsammak et al., [2]; study revealed also that a significant difference was found between the mean ADC values of malignant masses $\left(0.82 \times 10^{-3}\right.$ $\left.\mathrm{mm}^{2} / \mathrm{s}\right)$ and benign lesions $\left(1.44 \times 10^{-3} \mathrm{~mm}^{2} / \mathrm{s}\right)$, they had $88.9 \%$ sensitivity, $100 \%$ specificity and accuracy $88.9 \%$ when used $\left(1.19 \times 10^{-3} \mathrm{~mm}^{2} / \mathrm{s}\right)$ as a cut off value for differentiation benign from malignant endometrial lesions.

In a related context Keriakos and Darwish, [27] \& Cavusoglu et al., [16] reported that the mean ADC value was $\left(0.8 \times 10^{-3} \mathrm{~mm}^{2} / \mathrm{s}\right)$ for endometrial cancer with best cut off value of ADC to discriminate between benign and malignant lesions was $\left(1.2 \times 10^{-3} \mathrm{~mm}^{2} / \mathrm{s}\right)$.

Wang et al., [3] reported that various cut off ADC values have been used to differentiate malignant from benign endometrial lesions. These cut off ADC values ranged from $\left(0.908 \times 10^{-3} \mathrm{~mm}^{2} / \mathrm{s}\right)$ to $\left(1.28 \times 10^{-3} \mathrm{~mm}^{2} / \mathrm{s}\right)$. By applying the cut off ADC value of $\left(0.98 \times 10^{-3} \mathrm{~mm}^{2} / \mathrm{s}\right)$ in their study, they achieved $100 \%$ sensitivity, $97.1 \%$ specificity and accuracy $98.3 \%$.

The results of the previous studies were slightly higher than our results, According to Kececi et al., [26] and Wang et al., [3] the differences in ADC values in the studies can be explained by the difference in many technical variables that affect the ADC value such as different MRI units, pulse sequences, or b values.

Both in the light of the literature, as well as the results of our study, it can be said that DWI and ADC measurements have a high diagnostic efficacy in discrimination of endometrial cancer from benign diseases affecting the endometrium, since DWI is a non time consuming and safe technique without ionizing radiation that is not need contrast material, thus enabling its use in patients with impaired renal function, it can provide qualitative and quantitative valuable information to morphological MR sequences and can easily be added into standard imaging protocols using MRI.

\section{Limitations \& recommendations:}

The relatively small number of patients as the study was limited only to patients with histopatho- logically diagnostic lesions in order to obtain undebatable reference standards so further studies on a larger population are required to confirm our results.

DWI in the pelvis is still limited by technical problems that can affect image quality, as motion artifact additionally the low resolution of DWI that become more worse at higher $b$ value. Fused T2-WI and high $b$ value imaging with background body signal suppression (DWIBS) can improve anatomic data.

ADC measurements can be affected by the site, size, and form of the ROI. The circular ROIs placed in the selective region of the lesion were applied in our study. The selection of the area in the lesions can be subjective and might lead to some bias. Histogram analysis of the entire tumor may be a more accurate method to avoid sample selection bias.

\section{References}

1- WANG J., YU T., BAI R., SUM H., ZHAO X. and LI Y.: The value of the apparent diffusion coefficient in differentiating stage IA endometrial carcinoma from normal endometrium and benign diseases of the endometrium: Initial study at 3-T magnetic resonance scanner. J. Comput Assist Tomogr., 34 (3): 332-337, 2010.

2- ELSAMMAK A., SHEHATA S.M., ABULEZZ M. and GOUHAR G.: Efficiency of diffusion weighted magnetic resonance in differentiation between benign and malignant endometrial lesions. The Egyptian Journal of Radiology and Nuclear Medicine, 48 (3): 751-759, 2017.

3- WANG X., ZHAO Y., HU Y., ZHOU Y., YE X., LIU K., et al.: Evaluation and validation of the diagnostic value of the apparent diffusion coefficient for differentiating early-stage endometrial carcinomas from benign mimickers at 3T MRI. Oncotarget, 8 (28): 46390-46397, 2017.

4- RECHICHI G., GALIMBERTI S., SIGNORELLI M., FRANZESI C.T., PEREGO P., VALSECCHI M.G., et al.: Endometrial cancer: correlation of apparent diffusion coefficient with tumor grade, depth of myometrial invasion, and presence of lymph node metastasis. AJR, 197: 256-262, 2011.

5- MOTOSHIMA S., IRIE H., NAKAZONO T., KAMURA T. and KUDO S. Diffusion-weighted MR imaging in gynecologic cancers. J. Gynecol. Oncol., 22 (4): 275-287, 2011.

6- INOUE C., FUJII S., KANEDA S., FUKUNAGA T., KAMINOU T., KIGAWA J., et al. Apparent Diffusion Coefficient (ADC) Measurement in Endometrial Carcinoma: Effect of Region Interest Methods on ADC Values. Journal of Magnetic Resonance Imaging, 40: 157-161, 2014.

7- HABIB L.A., ALHAWARY M.M., ABD ELDAYEM E.H. and ABD ALGHANY A.F.: Role of MRI in Diagnosis of Endometrial Cancer. The Egyptian Journal of Hospital Medicine, 72 (10): 5505-5512, 2018. 
8- VERMOOLEN M.A., KWEE T.C. and NIEVELSTEIN R.A.J.: Apparent diffusion coefficient measurements in the differentiation between benign and malignant lesions: A systematic review. Insights Imaging, 3 (4): 395-409, 2012.

9- KARAKAS O., KARAKAS E., DOGAN F., KILICASLAN N., CAMUZCUOGLU A., INCEBIYIK A., et al. Diffusion-weighted MRI in the differential diagnosis of uterine endometrial cavity tumors. Wien Klin Wochenscr, 127 (7-8): 266-273, 2015.

10- BAKIR V.L., BAKIR B., SANLI S., YILDIZ S.O., LYIBOZKURT A.C., KARTAL M.G., et al.: Role of diffusionweighted MRI in the differential diagnosis of endometrioid and non-endometrioid cancer of the uterus. Acta. Radiol., 58 (6): 758-767, 2017.

11- KIERANS A.S., BENNETT G.L., HAGHIGHI M. and ROSENKRANTZ A.B.: Utility of conventional and diffusion-weighted MRI features in distinguishing benign from malignant endometrial lesions. Eur. J. Radiol., 83 (4): 726-732, 2014.

12- SHADY M.S., BAKRY M.A., MAZROA J.A. and GADELHAK B.N.: MR diffusion imaging in preoperative evaluation of depth of myometrial invasion in endometrial carcinoma. The Egyptian Journal of Radiology and Nuclear Medicine, 47: 611-619, 2016

13- ADDLEY H., MOYLE P. and FREEMAN S.: Diffusionweighted imaging in gynaecological malignancy. Clin. Radiol., 72 (11): 981-990, 2017.

14- DUARTE A.L., DIAS J.L. and CUNHA T.M.: Pitfalls of diffusion-weighted imaging of the female pelvis. Radiol. Bras., 51 (1): 37-44, 2018.

15- AHMED S.A., EL TAIEB H.A. and ABOTALEB H.: Diagnostic performance of sonohysterography and MRI diffusion in benign endometrial lesion characterization. The Egyptian Journal of Radiology and Nuclear Medicine, 49: 579-589, 2018

16- CAVUSOGLU M., CILIZ D.S., OZSOY A., DURAN S., ELVERICI E., ATALAY C.R., et al.: Diffusion-Weighted MRI of Postmenopausal Women wih Vaginal Bleeding and Endometrial Thickening: Differentiation of Benign and Malignant Lesions. Belgian Society of Radiology, 70: 1-10, 2016

17- SATO K., YUASA N., FUJITA M. and FUKUSHIMA Y.: Clinical application of diffusion-weighted imaging for preoperative differentiation between uterine leiomyoma and leiomyosarcoma. Am. J. Obstet. Gynecol., 210 (4): 368.e1-368.e8, 2014

18-ARLEO E.K., SCHWARTZ P.E., HUI P. and McCARTHY S.: Review of Leiomyoma Variants. AJR, 205: 912-921, 2015.

19- JHA R.C., ZANELLO P.A., ASCHER S.M. and RAJAN S.: Diffusion-weighted imaging (DWI) of adenomyosis and fibroids of the uterus. Abdom Imaging, 39: 562-569, 2014.

20- TAKEUCHI M. and MATSUZAKI K.: Adenomyosis: Usual and Unusual Imaging Manifestations, pitfalls, and problem-solving MR Imaging Techniques. RadioGraphics, 31: 99-115, 2011

21- KILICKESMEZ O., BAYRAMOGLU S., INCI E., CIMILLI T. and KAYHAN A.: Quantitative diffusion-magnetic resonance imaging of normal and diseased uterine zones. Acta. Radiol., 50 (3): 340-7, 2009.

22- TIAN T., ZHANG G.F., ZHANG H. and LIU H.: Intravoxel incoherent motion diffusion-weighted imaging in differentiating uterine fibroid from focal adenomyosis: Initial results. SpringerPlus, 5: 9, 2016.

23- LIMA L.L.A., PARENTE R.C.M., MAESTA I., AMIM JUNIOR J., REZENDE FILHO J.F., MONTENEGRO C.A.B., et al.: Clinical and radiological correlations in patients with gestational trophoblastic disease. Radiol. Bras., 49 (4): 241-250, 2016.

24- SEFIDBAKHT S., HOSSEINI F., BIJAN B., HAMEDI B. and AZIZI T.: Qualitative and Quantitative Analysis of Diffusion-Weighted Imaging of Gestational Trophoblastic Disease: Can It Predict Progression of Molar Pregnancy to Persistent Form of Disease? European Journal of Radiology, 88: 71-76, 2017.

25- HALDORSEN I.S. and SALVESEN H.B.: What Is the Best Preoperative Imaging for Endometrial Cancer? Curr. Oncol. Rep., 18 (4): 25, 2016.

26- KECECI I.S., NURAL M.S., ASLAN K., DANACI M., KEFELI M. and TOSUN M.: Efficacy of diffusionweighted magnetic resonance imaging in the diagnosis and staging of endometrial tumors. Diagn. Interv. Imaging, 97 (2): 177-86, 2016

27- KERIAKOS N.N. and DARWISH E.: Diffusion weighted imaging in suspicious uterine tumors; how efficient is it? The Egyptian Journal of Radiology and Nuclear Medicine, 49 (3): 838-845, 2018. 


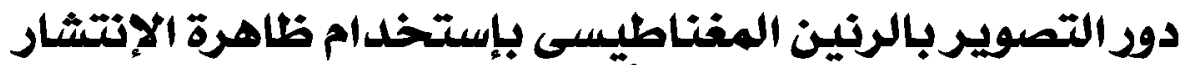

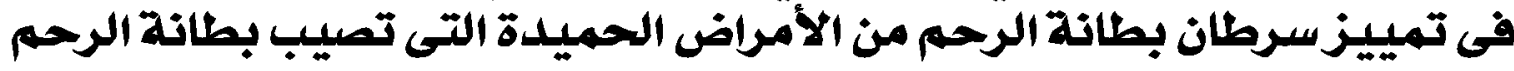

يعد سرطان بطانة الرحم واحد من أكثر الأورام الخبيثة التى تصيب الجهاز التناسلى اللنساء شيوعاً، وعادة يظهر كنزيف دموى بعد سن

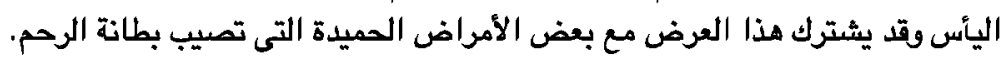

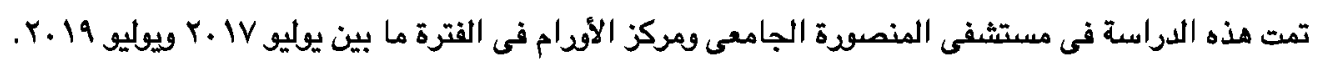

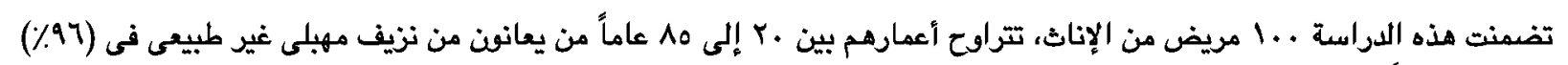

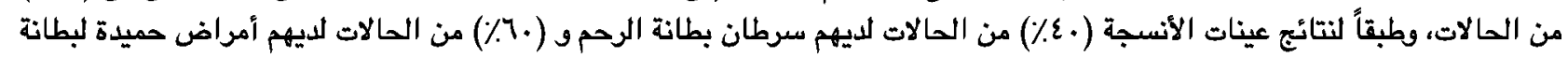

الرحم.

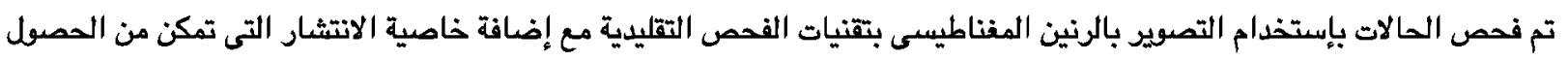

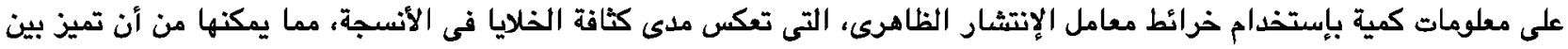
الأمراض الخييثة والحميدة. 